\title{
Estados físicos da água, calor sensível e calor latente: um jogo didático para o ensino de física com audiodescrição e braille
}

\author{
Bianca Martins Santos ${ }^{1}$, Ingrath Narrayany da Costa Nunes², Fernando Neri de Arruda ${ }^{3}$ \\ 1, 2, 3 Universidade Federal do Acre (UFAC)
}

Palavras-Chave: Estados físicos da água; Calor sensível e latente; Jogo didático; Audiodescrição; Braille.

\section{Introdução}

A inclusão escolar dos alunos com deficiência visual (cego) tem crescido muito nos dias atuais, de tal modo que os educadores precisam buscar diferentes estratégias de ensino nas diversas áreas de atuação, a fim de ampliar a qualidade do ensino. Por conseguinte, incluir é, sobretudo, disponibilizar aos alunos a possibilidade de dominar o saber que ele absorve do professor, destacando o modo excludente e inacessível com que a ciência, muitas vezes, tem sido tratada em sala de aula com alunos cegos (LIPPE; CAMARGO, 2009).

O aluno com deficiência visual necessita de adaptações especificas dos materiais de Física. Visto que para incluí-los nas aulas, além de utilizar imagens com elementos destacados em relevo e maquetes acessíveis. Em particular, no contexto de jogos didáticos, é possível trabalhar as adaptações através da Audiodescrição, tendo como objetivo a tradução lúdica daquilo que está sendo trabalhado, e legenda em braille. Ambos utilizados para auxiliar a leitura dos alunos cegos, garantindo assim a aquisição de conhecimentos sobre o mundo.

Mas, para que ocorra a inclusão, as pessoas com deficiência visual necessitam de recursos que garantam o processo de ensino, e o uso da Tecnologia Assistiva, no sentido de terem garantidos materiais adaptados à sua especificidade e que possibilitem a aprendizagem. Conforme destaca Bersch (2013), Tecnologia Assistiva (TA):

É uma ferramenta facilitadora do processo ensino aprendizagem e, consequentemente, da inclusão de alunos em todas as etapas da formação educacional, permitindo a acessibilidade destes, colocando-os em igualdade de condições para participarem, juntamente com as pessoas videntes, de conversas, atividades acadêmicas, dentre outras, a partir de conteúdos variados (BERSCH, 2013, p. 2).

Assim, a Tecnologia Assistiva tornou-se um instrumento fundamental no apoio pedagógico, e meio concreto de inclusão dos alunos com deficiência visual em instituições de todos os níveis. Neste contexto, o trabalho propõe um jogo para o ensino de física, sobre os conceitos de estados físicos da água; calor sensível e calor latente. Além da ideia do jogo ser inédita, este apresenta adaptações em relevo, braille e audiodescritas.

\section{Jogo proposto}

O jogo possui três andares de tabuleiros, no formato retangular com as bordas arredondadas. O primeiro andar representa o estado sólido, o segundo andar o estado líquido e o terceiro andar o estado gasoso. Em particular, optou-se por tomar como substância que compõem o sistema: a água. Assim, o primeiro andar representa o gelo; o segundo andar a água; e o terceiro andar o vapor d'água. Os andares do jogo foram confeccionados em MDF. O primeiro andar é a base da estrutura, e sobre ele, quatro hastes localizadas nas extremidades, apoiam o segundo andar. E sobre o segundo andar, outras quatro hastes, localizada nas extremidades, apoiam 0 terceiro andar. A estrutura é de encaixe, para ser desmontável e facilitar o transporte.

O jogo (Figura 1) consiste em uma "trilha de casas", porém as casas para serem percorridas pelos jogadores em cada andar do tabuleiro, são buracos vazados. O total de casas para cada jogador percorrer e fechar o caminho completo da trilha é formado por 12 casas: 1 ponto de partida, 6 casas numa trilha vermelha subindo os andares, e 5 casas numa trilha azul descendo os andares. O objetivo do jogo é percorrer o caminho vermelho subindo os andares, e descer os andares percorrendo o caminho azul. $O$ jogador que passar por todas casas do caminho e retornar ao ponto inicial primeiro, será o vencedor.

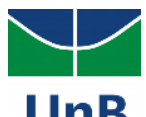


Figura 1 - Tabuleiro do jogo montado (esquerda) e composição completa do jogo: tabuleiro, peças, tradução lúdica por audiodescrição em braille e em áudio (direita).
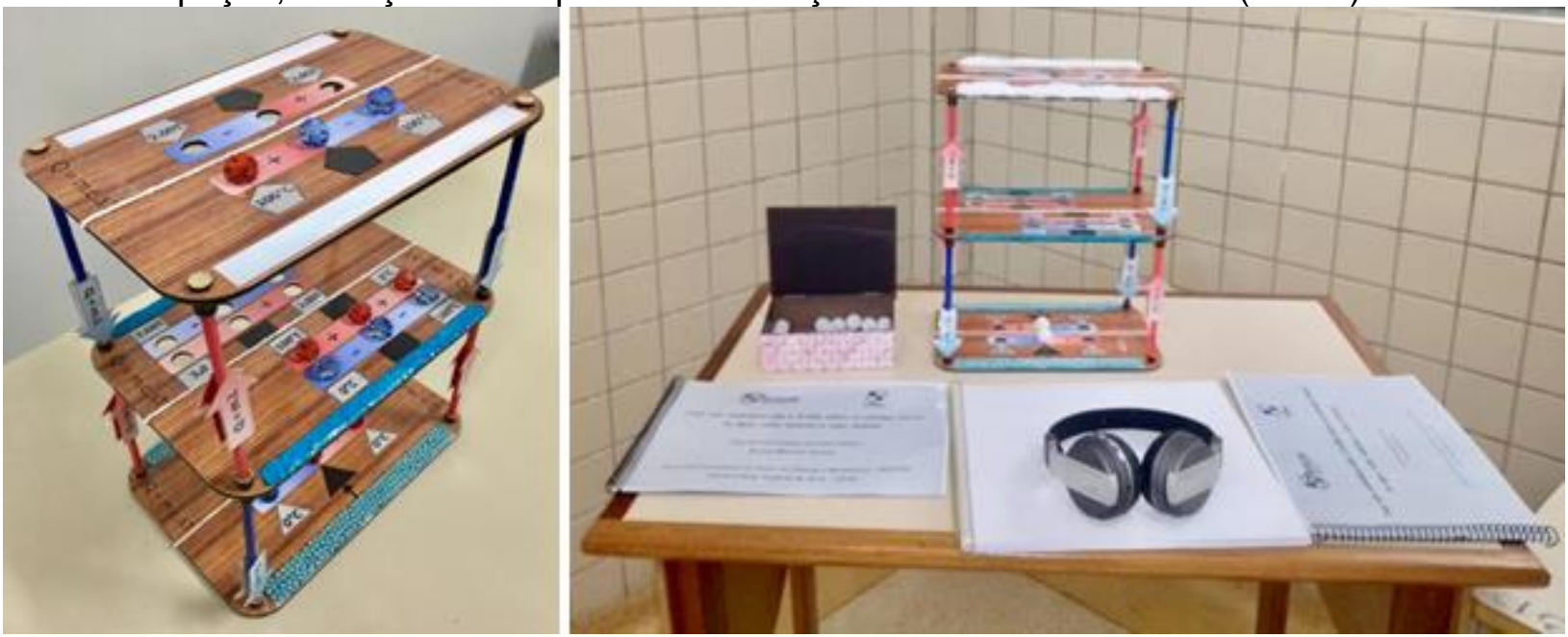

Fonte: Próprio autor.

De forma resumida, o jogo trabalha os seguintes conceitos físicos:

- Cálculo do calor necessário para variação de temperatura, sem que o estado físico da substância mude. Ou seja, o cálculo do calor sensível: $Q=m$. c. $\Delta T$, onde $m$ é a massa da substância, $c$ é o calor específico e $\Delta T=T_{f}-T_{i}$ é a variação de temperatura do sistema, temperatura final menos temperatura inicial.

- Cálculo do calor necessário para mudar o estado físico da matéria, mantendo a temperatura constante. Ou seja, o cálculo do calor latente: $Q=m$. $L$, onde $m$ é a massa da substância e $L$ é o calor latente envolvido na transformação.

- A forma como as partículas (átomos ou moléculas) compõem a substância em cada estado físico: organizadas, agregadas e movendo-se com pouca facilidade (sólido); menos organizadas, estado de agregação menor e movendo-se mais facilmente (líquido); e muito pouco organizadas, completamente livres e movendo-se com muita facilidade (gasoso).

- O conceito de que a temperatura é a medida da energia térmica dos corpos e está associada ao estado de agitação das partículas de um corpo.

- Conceito de que calor é a energia em trânsito entre o sistema e o ambiente.

\section{Momento da aplicação e resultados esperados}

O jogo será aplicado à uma turma de terceiro ano de ensino médio da rede pública de Rio Branco, dentro do projeto temático sobre "Água", proposto pela coordenação pedagógica, para ser trabalhado por todos os professores dentro das diversas componentes curriculares. A aplicação está prevista para outubro de 2019. Na turma existe um aluno com deficiência visual. Pretende-se com o jogo adaptado, promover uma situação de aprendizagem que comtemplem todos os alunos da turma.

\section{Referências}

BERSCH, R. Introdução à Tecnologia Assistiva. Porto Alegre - RS, 2013. LIPPE, E. M. O.; CAMARGO, E. P. O ensino de ciências e os seus desafios para inclusão: 0 papel do professor especialista. São Paulo: Scielo Books, editora Unesp, 2009. 